series passed an initial screening test that suggested to the surgeon the likelihood of a good outcome from operative intervention.

Andrew S. Wechsler, MD Medical College of Virginia P.O. Box 980645

Richmond, VA 23298-0645

$12 / 8 / 78747$

\section{Atrioventricular septal defect with subaortic stenosis: Extended valvular detachment and leaflet augmentation}

\section{To the Editor:}

We read with interest the recent report by Van Ardsell and colleagues ${ }^{1}$ regarding the different treatment options for subaortic stenosis associated with atrioventricular septal defect (AVSD). They pointed out the importance of leaflet augmentation and fibromyectomy to decrease the likelihood of recurrence of subaortic stenosis. We would like to further clarify the technical aspects of leaflet augmentation in AVSD when malattachment of the left superior leaflet is the predominant feature of an associated subaortic stenosis. The authors, when describing this surgical procedure, stated that "the superior bridging leaflet is detached from the anterior portion of the septal crest extending to the region just to the left of the left ventricular outflow tract" and that "the increased mitral aortic separation is excised." The left superior leaflet is thus detached at two different boundaries of the left ventricular outflow tract: (1) the septal insertion of the valvular leaflet and (2) the aorta-left atrioventricular (AV) valve continuity.

Leaflet augmentation with detachment of the valvular leaflet from the septal crest was first reported by Lappen and colleagues $^{2}$ and subsequently by DeLeon and colleagues ${ }^{3}$ in a patient in whom subaortic stenosis recurred after the surgical correction of a partial AVSD. The anatomic concepts leading to that treatment option were emphasized by Chang and Becker ${ }^{4}$ in Rastelli type A AVSD. Today, this procedure gains increased interest ${ }^{5}$ owing to the failure of more simple options that did not address the pathoanatomic features of the subaortic area in AVSD.

The importance of aorta-left AV valve continuity in the pathogenesis of a subaortic stenosis was underlined by Ebels and coworkers ${ }^{6}$ in their description of the "atrial fold." These authors proposed a sham repair with either an enlargement of this anatomic region using a diamond-shaped patch or a resection of the atrial fold in case of an associated left $A V$ valve replacement. Moreover, patch insertion at this level associated with a left $A V$ valve replacement avoids postoperative subaortic stenosis in AVSD. ${ }^{7}$

Keeping these important anatomic concepts in mind, we used leaflet augmentation in a 12-year-old girl who had been referred to our institution for native subaortic stenosis associated with an AVSD. Leaflet augmentation was accomplished by extending the detachment of the superior leaflet from the septal crest into the aorta-left AV valve continuity (Fig. 1). ${ }^{8}$ The young girl was still doing well 2 years later, without subaortic stenosis, with a moderate stenosis at the aortic level and a mild "mitral" insufficiency. Since this report, we observed, immediately after correction of a partial AVSD in a 3-year-old girl without Down syndrome, the occurrence of a subaortic stenosis with a systolic left ventricle-ascending aorta gradient of $37 \mathrm{~mm} \mathrm{Hg}$. One year later, a color-coded echocardiographic study revealed the progressive increase of the left ventricular outflow tract obstruction to a systolic gradient of $80 \mathrm{~mm} \mathrm{Hg}$. Using the same operative procedure associated with a fibromyectomy, we completely

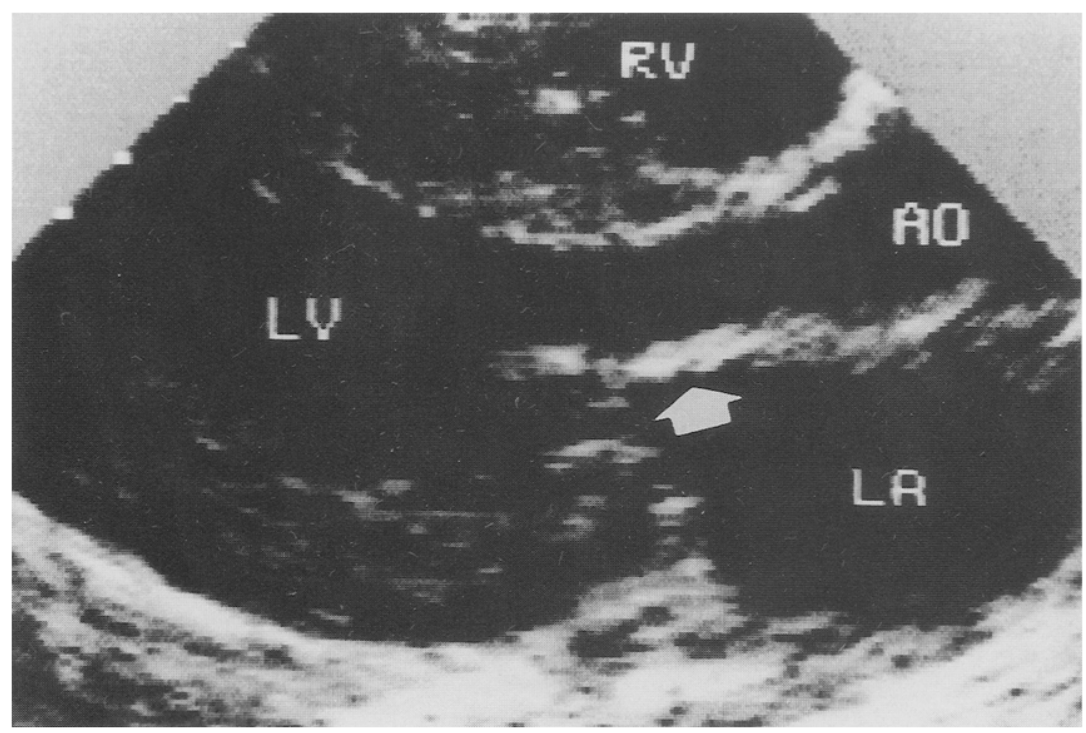

Fig. 1. Postoperative echocardiogram (parasternal longitudinal view): left AV valve augmentation at the level of the aorta-left AV valve continuity showing the polytetrafluoroethylene patch (arrow). AO, Aorta; $L A$, left atrium; $L V$, left ventricle; $R V$, right ventricle. 
relieved the subaortic stenosis. The "mitral" valve repair included a cleft closure and an annuloplasty. Today, 2 years later, there is no recurrence of the left ventricular outflow tract obstruction or of the left AV valve insufficiency.

We would like to congratulate the authors on their large experience and we fully agree with their inferences. Nevertheless, we believe that it is important to distinguish between the two different aspects of the left superior leaflet detachment that could be performed before its augmentation. In our opinion, detachment of the leaflet at the level of the septal crest is sometimes necessary to avoid subaortic stenosis after a primary repair of the anatomic type of AVSD that is likely to fail (i.e., partial and Rastelli type A AVSD). A further extension of the detachment in the aorta-left $A V$ valve continuity might be appropriate only in an already present or recurrent left ventricular outflow tract obstruction because of its inherent risks for the left $A V$ valve physiology.

Lö̈ Macé, $M D$,

Patrice Dervanian, $M D$,

Thierry Folliguet, $M D$,

Jean-Félix Verrier, $M D$,

Jean Losay, $M D$,

Jean-Yves Neveux, $M D$

Department of Cardiovascular and

Pediatric Cardiac Surgery

Marie Lannelongue Hospital and Paris-Sud University

133 avenue de la Résistance

92350 Le Plessis Robinson, France

\section{REFERENCES}

1. Van Ardsell GS, Williams WG, Boutin C, Trusler GA, Coles JG, Rebeyka IM, et al. Subaortic stenosis in the spectrum of atrioventricular septal defects: solutions may be complex and palliative. J Thorac Cardiovasc Surg 1995;110:1534-42.

2. Lappen RS, Muster AJ, Idriss FS, Riggs TW, Ilbawi M, Paul $\mathrm{MH}$, et al. Masked subaortic stenosis in ostium primun atrial septal defect: recognition and treatment. Am J Cardiol 1983;52: $336-40$.

3. DeLeon SY, Ilbawi MN, Wilson WR Jr, Arcilla RA, Thilenius OG, Bharati S, et al. Surgical options in subaortic stenosis associated with endocardial cushion defects. Ann Thorac Surg 1991;52:1076-83.

4. Chang CI, Becker AE. Surgical anatomy of left ventricular outflow tract obstruction in complete atrioventricular septal defect: a concept for operative repair. $J$ Thorac Cardiovasc Surg 1987;94:897-903.

5. Starr A, Hovaguimian H. Surgical repair of subaortic stenosis in atrioventricular canal defects. J Thorac Cardiovasc Surg 1994;108:373-6.

6. Ebels T, Ho SY, Anderson RH, Meijboom EJ, Eijgelaar A. The surgical anatomy of the left ventricular outflow tract in atrioventricular septal defect. Ann Thorac Surg 1986;41:483-8.

7. McGrath LB, Kirklin JW, Soto B, Bargeron LM Jr. Secondary left atrioventricular valve replacement in atrioventricular septal (AV canal) defect: a method to avoid left ventricular outflow tract obstruction. J Thorac Cardiovasc Surg 1985;89:483-8.

8. Macé L, Dervanian P, Folliguet T, Grinda JM, Losay J, Neveux Y. Atrioventricular septal defect with native subaortic stenosis: correction by extended valvular detachment. J Thorac Cardiovasc Surg 1994;107:943-5.

\section{Reply to the Editor:}

Macé and colleagues correctly infer that left atrioventricular (AV) valve augmentation in patients having atrioventricular septal defects (AVSDs) and subaortic stenosis may not be inconsequential. These are often redo operations that limit the potential for use of autologous pericardium. Other materials may have less longevity. Stress at the suture line might also cause disruption.

Detachment of the left superior leaflet, only from the septal crest, followed by leaflet augmentation effectively converts the anterior portion of the defect to a Rastelli type $\mathrm{C}$ lesion. ${ }^{1}$ This is a lower risk procedure that has its place in the treatment of AVSDs and outlet narrowing.

Patients with AVSDs having recurrent subaortic stenosis are a particular challenge. The outflow angle may be a marker for risk of subaortic stenosis. The outflow angle is defined by the angle created between the plane of the outlet septum and the plane of the closed left-sided anterior leaflet apparatus. ${ }^{2}$ Normal hearts have an angle approaching 90 degrees. The outflow angle in AVSDs varies but can be as small as zero degrees or approach normal. A narrow angle demonstrates an elongated outflow tract. This is a substrate for development of subaortic stenosis. ${ }^{3}$ We hypothesize that an increase in the outflow angle may lessen the incidence of recurrent subaortic stenosis. The largest effective increase in the outflow angle is achieved by detaching the left superior bridging leaflet from the septal crest and extending the incision anteriorly and laterally to include excision of the increased aorta-left AV valve continuity. This area is then generously augmented with a patch. A subaortic myectomy is also performed.

Because of the risk for the combined approach we perform standard subaortic resection and myectomy as a first line of treatment. Leaflet augmentation with subaortic myectomy or modified valve-sparing aortoventriculoplasty $^{4}$ is performed only in the event of recurrence and if the topography of the left ventricular outflow tract is significantly elongated and narrow.

$$
\begin{array}{r}
\text { Glen Van Arsdell, } M D \\
\text { William G. Williams, MD, FRCSC } \\
\text { Robert M. Freedom, MD, FRCPC } \\
\text { Hospital for Sick Children, Toronto, Canada } \\
\text { University of Toronto } \\
\text { Toronto, Ontario, Canada }
\end{array}
$$

\section{REFERENCES}

1. Starr A, Hovaguimian H. Surgical repair of subaortic stenosis in atrioventricular canal defects. J Thorac Cardiovasc Surg 1994;108:373-6.

2. Van Arsdell GS, Williams WG, Boutin C, Trusler GA, Coles JG, Rebeyka IM, et al. Subaortic stenosis in the spectrum of atrioventricular septal defects: solutions may be complex and palliative. J Thorac Cardiovasc Surg 1995;110:1534-42.

3. Gewillig M, Daenen W, Dumoulin M, Van Der Hanwaert L. Rheologic genesis of discrete subvalvular aortic stenosis: a Doppler echocardiographic study. J Am Coll Cardiol 1992;19: 181-824.

4. Kirklin JW, Barratt-Boyes BG, editors. Cardiac surgery. New York: John Wiley, 1986:971-1012. 